\title{
Determinants of Enrolment for Community Based Health Insurance Scheme among Agro-pastoralist communities of Aw-barre District in Somali region of Ethiopia: Unmatched case control study.
}

Abdifatah Elmi ( $\nabla$ abefarah@unicef.org )

Jigjiga University https://orcid.org/0000-0003-1636-9518

Olusola Oladeji

UNICEF Ethiopia

Ann Robins

UNICEF Ethiopia

Ahmed Tahir

Jigjiga University

Research

Keywords: Community Based Health Insurance, Determinants, Enrollment, Agro-pastoral, Somali region, Ethiopia

Posted Date: September 27th, 2021

DOl: https://doi.org/10.21203/rs.3.rs-921599/v1

License: (c) (i) This work is licensed under a Creative Commons Attribution 4.0 International License.

Read Full License 


\section{Abstract}

\section{Background}

Ethiopia launched community-based health insurance scheme in 2011 as part of the revised health care financing strategy to ensure universal health coverage and implementation has started in most part of the country since the launching of the scheme. However, the roll out of the scheme started in Somali Region in 2020-much later the rest of the country. The aim of this study was to assess determinants of enrollment of community-based health insurance among households in Awbarre Woreda, Somali Region, Ethiopia

Methods

Community based unmatched case control study using a mixed approach of quantitative and qualitative methods was conducted between March and April 2021 and the study participants were selected using multi-stage sampling technique. The quantitative method used interviewer administered structured questionnaire among 216 participants (54 enrolled and 162 non-enrolled), while the qualitative method used key informant interview and focus group discussions in two rural and two urban kebeles of the woreda. The quantitative data was analyzed using SPSS version 20 and thematic analysis was used for the qualitative data. Multivariable logistic regression was used to determine the determinants of enrollment for the community-based health insurance and statistical significance was set at $p$ value of $<5 \%$.

Result

Awareness about CBHI scheme AOR = 9.41(1.16,76.19), households income AOR = 2.73(0.77, 9.57); and being a member of community-based solidarity groups $A O R=2.88(1.17,7.12)$ were the determinants for $\mathrm{CBHI}$ enrollment and reaffirmed by the qualitative findings.

\section{Conclusions}

The enrollment for community-based insurance was determined by being well informed about the scheme, household income, and being a member of solidarity groups at community level. Given the early stage of implementation, enhancing sensitization of the community about the scheme using various community platforms, promotion of the existing community based solidarity groups/associations, diligent targeting of the poor households/indigents and ensuring linkage with any existing social protection program would help to increase enrolment for the scheme.

\section{Introduction}

Community Based Health Insurance $(\mathrm{CBHI})$ is a type of health insurance program that provides financial protection against the cost of illness and improving access to health care services for communities engaged in the informal sector. Universal health coverage means that all people have access to health 
services they need when and where they need them without financial hardship [1]. It includes the full range of essential health services, from health promotion to prevention, treatment, rehabilitation, and palliative care [1,2]. The progress towards this aspiration seems poor [3] particularly for countries whose fiscal capacity is low and whose social health insurance for the employed sector is absent or very small, thus limiting the mobilization of additional resources from payroll contributions. Financing health care in most developing countries greatly relies on out-of-pocket payments which contributes to unacceptably high burdens of preventable diseases and deaths $[4,5]$ with most donors and global health initiatives such as the Global Fund focusing on specific diseases or interventions rather than the broader health system.

Countries with a high share of out-of-pocket payments are more likely to have a high proportion of households facing catastrophic health expenditure-defined as spending more than $40 \%$ of household consumption expenditure, excluding food, on health, more than $25 \%$ of non-food consumption expenditure of households on health, or more than $10 \%$ of total household consumption expenditure on health [6]. The available evidence clearly demonstrates that health insurance can be an alternative to user fees as a health financing mechanism. The strong evidence that Community Based Health Insurance( $\mathrm{CBHI}$ ) and Social Health Insurance (SHI) can improve financial protection and enhance service utilization patterns [7], but the weaker evidence that $\mathrm{CBHI}$ and $\mathrm{SHI}$ can foster social inclusion of specific vulnerable groups in Low middle income countries (LMIC) $[8,9]$.

Ethiopia endorsed a health care financing strategy in 1998 that envisioned a wide range of reform initiatives launch of health to remove financial barriers, enhance equity, increase health service utilization rate and improve quality of care by increasing resources available for health facilities[10]. In its revised strategy (2017-2025), Ethiopia envisioned to ensure universal health coverage through primary health care by 2035 [11]. The Per capita spending is $\$ 33.2$ which is far below the globally recommended $\$ 86$ per capita estimated to make essential health care services available in low-income countries. In terms of spending, the government spends $8 \%$ of government budget on health sector which is below the Abuja target of $15 \%$ and the out-of-pocket expenditure is also still high standing at $31 \%$ of total health expenditure [12].

In Ethiopia, Community-based health insurance (CBHI) scheme was launched and piloted in 2011 and is among the avenues designed to contribute to reduction of out-pocket payments and realization of universal health coverage. The contribution (premium) is collected from the households at the pre-set flat rate meaning equal amount of payment is levied to every household regardless of their household characteristics such income and family size [33]. With the assumption that $85 \%$ of the total population is involved in informal sector and the country has $100+$ million populations, $\mathrm{CBHI}$ enrollment coverage in 2012 fiscal year (2019/20) accounts about $37 \%$ of population in informal sector. Geographically, the number of districts implementing $\mathrm{CBHI}$ in Ethiopia was 1100 districts in 2020 which translated to a coverage of $75 \%$ compared to the 2020 target achieving $80 \%$ of all districts to have $80 \% \mathrm{CBHI}$ coverage. However, majority of these $\mathrm{CBHI}$ woreda are concentrated in four big regions and the capital city of the country [13]. 
Somali region is one of Ethiopia's four Developing Regional States (DRS) and predominantly inhabited by pastoralists (85 per cent), faces developmental inequities and has shown less improvement or lagging in key health outcomes compared to the national average [14]. CBHI was launched in four districts (4\%) of this region in 2020-almost ten years behind the other regions of the country. However, implementation has just started only in Aw-barre district with an estimated household of 56,896 and a very low enrolment rate of roughly $16 \%$ unlike the national target coverage of $80 \%$ set for districts [15]. Thus, it is against this background that this study was aimed at identifying determinant factors for $\mathrm{CBHI}$ scheme enrolment in the district and to inform strategies to be implemented in improving the enrolment rate of the scheme in the region.

\section{Methodology}

\section{Study area}

Aw-barre district is $72 \mathrm{~km}$ North of Jigjiga-the capital of Somali region and is first district to start CBHI implementation in Somali region of Ethiopia. Administratively, the district is composed of 44 Villages (kebeles) arranged in six CBHI clusters and its population is projected to be 382,569 based on the 2007 national census conducted by the Central Statistical Agency of Ethiopia [15]. The number of households enrolled in $\mathrm{CBH}$ scheme are 10,100 which roughly translates in to $16 \%$ registration rate (District estimation). The district has four health centers and 46 health posts providing primary health care services to district population.

\section{Study duration}

The study was conducted in Aw-barre district between March 24 to April 24, 2021.

\section{Study design}

The study design was community based unmatched case control study (enrolled and non-enrolled members) using a mixed approach of quantitative and qualitative methods.

\section{Source and study populations}

The source population were all households residing in Aw-barre district at least in the last six months before the study.

\section{Sample size estimation}


The sample size was computed using Epi Info ${ }^{\mathrm{TM}} 7$ software [16] with the following assumptions: $80 \%$ statistical power with a level of significance at $5 \%$, Odds ratio of 4.16 [17] and a case to control ratio of 1:3. The estimated final sample size was 216 (54 enrolled and 162 non-enrolled) using the doubleproportions formula.

\section{Sampling methods and procedure}

The quantitative part of the study was conducted using multi-stage cluster sampling technique. In the first stage, ten kebeles(villages) were selected by simple random sampling out of 44 kebeles which are under six $\mathrm{CBHI}$ clusters. In the second stage, $216 \mathrm{HHs}$ were selected using probability proportional to size of households in villages. A "Kebele" is the smallest governmental administrative unit, and on average has a population of 5000 people (Fig1).

The qualitative data was collected using focus group discussions (FGDs) and Key Informant Interviews (KIIs) at district and regional level to triangulate with the findings from quantitative part. Four FGDs were done in two purposively selected kebeles (one rural and one urban) for both enrolled and non-enrolled households. Key informants were woreda/district health office representative, woreda CBHI coordinator and Regional Health Bureau focal point for CBHI.

\section{Data collection tools and techniques}

A structured questionnaire was administered by trained enumerators to head of selected households and a Semi-structured interview guide used for the FGD and KII. The questionnaire and interview guide were prepared first in English and translated to Somali and then translated back to English to keep its consistency.

\section{Data analysis}

Data were entered and analysis was performed with SPSS V.20. Descriptive statistics was calculated to describe the study objectives in terms of appropriate variables. Binary and multi-variate logistic regression analyses were performed to identify determinant variables for enrollment of CBHI scheme. Variables with a $p$-value of $\leq 0.25$ on bivariate logistic regression analysis were used for multivariable logistic regression analysis to find the adjusted odds ratio at $95 \% \mathrm{Cl}$ and $p$-value $<0.05$.

For the qualitative data, notes were taken, and the entire discussion was audio recorded and later transcribed for analysis. Analysis was done using a thematic analytic approach. Emerging themes were summarized under different thematic areas and quotes from participants were presented textually.

\section{Results}


Socio-demographic profile of Respondents

Table 1 shows a total of 216 households participated in the study (54 cases and 162 controls) with 100\% response rate. Among the participants enrolled into the scheme, 14 (24.1\%) were rural households compared to $41(75.9 \%)$ urban households. Education, household income ( $>16000$ ETB) showed significant difference between the cases and controls. Sex of the household head, size of the household and place of residence have not shown any significance difference (Table 1).

Table 1. Bivariate analysis of socio-economic and demographic characteristics of respondents, Awbarre district, Somali region, Ethiopia 2021(n=216). 


\begin{tabular}{|c|c|c|c|c|}
\hline \multirow[t]{2}{*}{ Variables } & \multicolumn{2}{|c|}{ CBHI Enrolment } & \multirow[t]{2}{*}{ Crude OR } & \multirow[t]{2}{*}{$\mathrm{P}=$ value } \\
\hline & No (162) & Yes (54) & & \\
\hline \multicolumn{5}{|l|}{ Age of household head } \\
\hline $18-30$ & $36(22.2 \%)$ & $14(25.9 \%)$ & $1.91(0.76,4.74)$ & 0.165 \\
\hline $31-40$ & $65(40.1 \%)$ & $24(44.4 \%)$ & $1.8(0.78,4.09)$ & 0.168 \\
\hline $41-50$ & $38(23.5 \%)$ & $9(16.7 \%)$ & $0.13(0.02,1.05)$ & 0.056 \\
\hline$>50$ & $23(14.2 \%)$ & $7(13.0 \%)$ & 1 & \\
\hline \multicolumn{5}{|l|}{ Sex of household head } \\
\hline Female & $81(50 \%)$ & $29(53.7 \%)$ & $1.16(0.63,2.15)$ & 0.637 \\
\hline Male & $81(50 \%)$ & $25(46.3 \%)$ & 1 & \\
\hline \multicolumn{5}{|c|}{ Marital status of household head } \\
\hline Divorced/Widowed & $11(6.9 \%)$ & $1(1.8 \%)$ & $0.39(0.04,4.35)$ & 0.447 \\
\hline Married & $136(85.5 \%)$ & $52(91.2 \%)$ & $1.57(0.43,5.74)$ & 0.495 \\
\hline Single & $12(7.5 \%)$ & $4(7 \%)$ & 1 & \\
\hline \multicolumn{5}{|l|}{ Educational status } \\
\hline No formal education & $120(74.1 \%)$ & $33(61.1 \%)$ & $0.19(0.06,0.66)$ & 0.008 \\
\hline Primary & $37(22.8 \%)$ & $14(25.9 \%)$ & $0.27(0.07,0.99)$ & 0.049 \\
\hline Secondary/post-secondary & $5(3.1 \%)$ & $7(13 \%)$ & 1 & 1 \\
\hline \multicolumn{5}{|l|}{ Occupation } \\
\hline Agro-pastoralist & $91(56.2 \%)$ & $25(46.3 \%)$ & $0.41(0.06,2.60)$ & 0.346 \\
\hline Daily laborer & $42(25.9 \%)$ & $15(27.8 \%)$ & $0.54(0.8,3.52)$ & 0.516 \\
\hline Merchant & $26(16.0 \%)$ & $12(22.2 \%)$ & $0.69(0.10,4.70)$ & 0.707 \\
\hline Other & $3(1.9 \%)$ & $2(3.7 \%)$ & 1 & \\
\hline \multicolumn{5}{|l|}{ Place of residence } \\
\hline Rural & $53(32.7 \%)$ & $13(24.1 \%)$ & $0.65(0.32,1.32)$ & 0.235 \\
\hline Urban & $109(67.3 \%)$ & $41(75.9 \%)$ & 1 & \\
\hline \multicolumn{5}{|l|}{ Elderly person above 65 in $\mathrm{HH}$} \\
\hline No & $115(71.0 \%)$ & $40(74.1 \%)$ & $1.17(0.58,2.34)$ & 0.663 \\
\hline Yes & $47(29.0 \%)$ & $14(25.9 \%)$ & 1 & \\
\hline
\end{tabular}




\begin{tabular}{|lllll|}
\hline Household Size & & & \\
\hline$<3$ & $8(4.9 \%)$ & $2(3.7 \%)$ & $0.70(0.14,3.48)$ & 0.665 \\
\hline-4 & $23(14.2 \%)$ & $10(18.5 \%)$ & $1.22(0.52,2.85)$ & 0.646 \\
$4-6$ & $44(27.2 \%)$ & $11(20.4 \%)$ & $0.7(0.32,1.53)$ & 0.372 \\
\hline 6 & $87(53.7 \%)$ & $31(57.4 \%)$ & 1 & \\
\hline Annual household income (ETB) & & & & \\
\hline$<8,000$ & $87(53.7 \%)$ & $20(37.0 \%)$ & 1 & 0.757 \\
\hline $8,001-16,000$ & $54(33.3 \%)$ & $14(25.9 \%)$ & $1.13(0.53,2.42)$ & 0.040 \\
\hline $16,001-28,000$ & $12(7.4 \%)$ & $8(14.8 \%)$ & $2.90(1.05,8.03)$ & 0.001 \\
\hline$>28,000$ & $9(5.6 \%)$ & $12(22.2 \%)$ & $5.80(2.15,15.63)$ & 0 \\
\hline
\end{tabular}

Table 2 shows result of the bivariate analysis households with information about $\mathrm{CBHI}$ were more likely to enroll into $\mathrm{CBHI}$ scheme compared to those with no information $\mathrm{COR}=12.5(1.67,94.23)$. Being a member of a local solidarity group like local money saving association were more likely to go for $\mathrm{CBHI}$ enrollment $\mathrm{COR}=2.23(1.15,4.31)$. Also, households who considered the premium (preset payment of 250 ETB) as affordable were more likely to enroll in the $\mathrm{CBHI}, \mathrm{COR}=2.71(1.08,6.80)$. (Table 2).

Table 2. Bivariate analysis of household characteristics of respondents and CBHI enrolment, Awbarre district, Somali region, Ethiopia April 2021 $(n=262)$. 


\begin{tabular}{|c|c|c|c|c|}
\hline \multirow{2}{*}{$\begin{array}{l}\text { Variables } \\
\text { Heard of CBHI? }\end{array}$} & \multicolumn{2}{|c|}{ CBHI Enrolment } & \multirow[t]{2}{*}{ COR } & \multirow[t]{2}{*}{$P=$ value } \\
\hline & $\begin{array}{l}\text { No } \\
\text { (Control) }\end{array}$ & $\begin{array}{l}\text { Yes } \\
\text { (Case) }\end{array}$ & & \\
\hline No & $31(19.1 \%)$ & $1(1.9 \%)$ & 1 & \\
\hline Yes & $131(80.9 \%)$ & $53(98.1 \%)$ & $12.5(1.67,94.23)$ & 0.014 \\
\hline \multicolumn{5}{|l|}{ Source of info about CBHI? For enrolled. } \\
\hline TV/radio & $5(3.1 \%)$ & $4(7.4 \%)$ & & \\
\hline House to house awareness creation & $11(6.8 \%)$ & $3(5.6 \%)$ & & \\
\hline $\mathrm{CBHI}$ officials in Public meeting & $34(21.0 \%)$ & $9(16.7 \%)$ & & \\
\hline Health professionals in health facilities & $13(8.0 \%)$ & $8(14.8 \%)$ & & \\
\hline Neighbor/friends & $28(17.3 \%)$ & 2(3.7\%) & & \\
\hline Mixed & $40(24.7 \%)$ & $27(50.0 \%)$ & & \\
\hline Not heard & $31(19.1 \%)$ & $1(1.9 \%)$ & & \\
\hline \multicolumn{5}{|l|}{$\begin{array}{l}\text { Perceived affordability of the premium } \\
\text { ( } 250 \text { ETB) per year }\end{array}$} \\
\hline No & $41(25.3 \%)$ & $6(11.1 \%)$ & 1 & \\
\hline Yes & $121(74.7 \%)$ & $48(88.9 \%)$ & $2.71(1.08,6.80)$ & 0.034 \\
\hline \multicolumn{5}{|l|}{ Enrolled in a solidarity group } \\
\hline No & $126(77.8 \%)$ & $33(61.1 \%)$ & 1 & \\
\hline Yes & $36(22.2 \%)$ & $21(38.9 \%)$ & $2.23(1.15,4.31)$ & 0.018 \\
\hline \multicolumn{5}{|l|}{ Trust on the CBHI scheme? } \\
\hline No & $20(12.3 \%)$ & $4(7.4 \%)$ & 1 & \\
\hline Yes & 142(87.7\%) & $50(92.6 \%)$ & $1.76(0.57,5.40)$ & 0.323 \\
\hline \multicolumn{5}{|l|}{ Chronic illness in the Household? } \\
\hline Does not exist & $126(77.8 \%)$ & $37(68.5 \%)$ & & 1 \\
\hline Exists & $36(22.2 \%)$ & $17(31.5 \%)$ & $1.61(0.81,3.19)$ & 0.173 \\
\hline \multicolumn{5}{|l|}{ Time to reach to nearest health facility? } \\
\hline$<30$ minutes & $129(79.6 \%)$ & $51(94.4 \%)$ & $\begin{array}{l}5.53(0.71 \\
43.19)\end{array}$ & 0.103 \\
\hline$>60$ minutes & 19(11.7\%) & $2(3.7 \%)$ & $\begin{array}{l}1.47(0.12 \\
17.91)\end{array}$ & 0.761 \\
\hline
\end{tabular}




\section{Determinants of CBHI enrolment in Aw-barre district.}

Table 3 shows the results of multivariate analysis, variables considered into multivariate logistic regression model were all those with P-value $<0.25$ at bivariate analysis level.

At multivariate level, household with high income, being a member of a solidarity group and having awareness about $\mathrm{CBH}$ scheme were found to be the determinants of $\mathrm{CBHI}$ enrollment.

Households with better income were almost four times more likely to enroll $\mathrm{CBH}$ than low income households $(A O R=3.56(1.03,12.30), P=0.044)$. Similarly, Households with no information about $C B H I$ service were nine times more likely to enroll than households with no information about $\mathrm{CBH}$ scheme, $(A O R=9.41(1.16,76.19), P=0.036)$. Moreover, households which were members of a solidarity group like saving association or other community-based organizations were almost three times more likely to enroll than non-members $(\mathrm{AOR}=2.88(1.17,7.12), \mathrm{P}=0.022)$.

Table 3. Determinants of CBHI enrolment using multivariable analysis in Aw-barre district, Somali Region, Ethiopia, April 2021(n=262). 


\begin{tabular}{|c|c|c|c|c|}
\hline \multirow{2}{*}{$\begin{array}{l}\text { Variables } \\
\text { Heard of CBHI? }\end{array}$} & \multicolumn{2}{|c|}{ CBHI Enrolment } & \multirow[t]{2}{*}{ AOR } & \multirow[t]{2}{*}{$P=$ value } \\
\hline & $\begin{array}{l}\text { No } \\
\text { (Control) }\end{array}$ & $\begin{array}{l}\text { Yes } \\
\text { (Case) }\end{array}$ & & \\
\hline No & $31(19.1 \%)$ & $1(1.9 \%)$ & & \\
\hline Yes & $131(80.9 \%)$ & $53(98.1 \%)$ & $9.41(1.16,76.19)$ & 0.036 \\
\hline \multicolumn{5}{|c|}{$\begin{array}{l}\text { Perceived affordability of the premium } \\
\text { ( } 250 \text { ETB) per year }\end{array}$} \\
\hline No & $41(25.3 \%)$ & $6(11.1 \%)$ & & \\
\hline Yes & $121(74.7 \%)$ & $48(88.9 \%)$ & $1.68(0.57,5.01)$ & 0.347 \\
\hline \multicolumn{5}{|c|}{ Enrolled in a solidarity group } \\
\hline No & $126(77.8 \%)$ & $33(61.1 \%)$ & 1 & \\
\hline Yes & $36(22.2 \%)$ & $21(38.9 \%)$ & $2.88(1.17,7.12)$ & 0.022 \\
\hline \multicolumn{5}{|c|}{ Household Income in ETB } \\
\hline$<8000$ & $87(53.7 \%)$ & $20(37.0 \%)$ & & \\
\hline $8001-16000$ & $54(33.3 \%)$ & $14(25.9 \%)$ & $0.73(0.31,1.75)$ & 0.484 \\
\hline $16001-28,000$ & $12(7.4 \%)$ & $8(14.8 \%)$ & $2.73(0.77,9.57)$ & 0.118 \\
\hline$>28,000$ & $9(5.6 \%)$ & $12(22.2 \%)$ & $\begin{array}{l}3.56(1.03 \\
12.30)\end{array}$ & 0.044 \\
\hline
\end{tabular}

\section{Findings from qualitative part}

Four FGDs were conducted - two among CBHI enrolled households and two among non-enrolled households in rural and urban kebeles. The common reason for joining $\mathrm{CBHI}$ was the need to get accessible health care services free of charge for family members.

"I registered to get medicines and free health care services for my family"

[CBHI member in Lafa-issa kebele of Awbarre woreda].

For non-CBHI members, the commonest reasons for not being enrolled were not heard of $\mathrm{CBHI}$ followed by unaffordable payment.

"It is through this FGD session that I first hear community-based health Insurance scheme"

[Non-CBHI member in Lafa-issa kebele of Awbarre woreda].

Regarding indigents targeting, FGD members from different kebeles had varied views. Whilst some FGD members claimed that the poor were identified fairly in their kebele and their payments were covered, 
other FGD members from the other kebele claimed that indigent identification and targeting did not happen at all.

"Membership registration in this kebele was based only on the ability to contribute 250 Birr, no single indigent was registered".

[CBHI member in Abayfulan kebele, Awbarre district].

"The selection process for the poor households were transparent and fair in my view. And I think the process was based on the economic severity of the households. I can say needy households were not left out"

[CBHI member in Lafaissa, Aw-barre district].

Key informants at regional and district level have described commendable progress of the scheme within a short period and the challenges that came along with it.

"Some of the major achievements include helping the community understand the benefits of insurance, managing many poor households and people with chronic illnesses to get enrolled into the scheme and receive free service including the laboratory services. But some challenges such as community misunderstandings require further work" -

[Awbarre woreda, $\mathrm{CBHI}$ coordinator]

\section{Discussion}

This study identified determinants of household enrolment for community-based health insurance (CBHI) in Aw-barre district of Somali region, Ethiopia. Determinants of enrolment include awareness about CBHI, Household income, perceived affordability of the premium and being a member of a solidarity group.

The study found that having information about $\mathrm{CBHI}$ was a key determinant identified to affect enrolment of the $\mathrm{CBHI}$ scheme in the study area. Households with information about $\mathrm{CBHI}$ were more likely to get enrolled into the scheme and the poor enrollment is related to inadequate sensitization at community level even though the scheme is at the early stage of implementation. This is similar to findings in other studies done in Ethiopia [16, 17,19, 25, 30], Nigeria [18], Uganda [22] and Cameroon [27] which identified inadequate knowledge and understanding of insurance and $\mathrm{CBHI}$ principles are some of the obstacles to enrolment. Another study also found inadequate client education, and limited community engagement as factors that threaten the scheme's sustainability [39]. Similarly, a previous study in Ethiopia found that knowledge of $\mathrm{CBHI}$ not only determines the enrolment but also associated with a drop out from the scheme [38].

This study also found that being enrolled in a solidarity group was an important determining factor for household enrolment of $\mathrm{CBHI}$ with those who are members of any form of a solidarity group more likely 
to get enrolled into the scheme. This goes in line with a study that reported solidarity and trust encourages groups susceptible to risk to put together their resources for common use [20] and is also consistent with other studies done in Ethiopia [17] and Cameroon [27]. Moreover, community solidarity is a form of a social capital at community level that positively impact households' decision for health insurance, which in turn increases the demand and sustainability of $\mathrm{CBHI}$ and could serve as a platform for sensitization on CBHI scheme[20, 27, 28, 42].

Household income was found to be another determinant for $\mathrm{CBHI}$ enrolment. Households with higher annual income tended to be enrolled more into the scheme compared to those with less income. This is comparable with other studies with similar findings $[17,22,24,26,29,30]$. A systematic review of factors affecting uptake of $\mathrm{CBHI}$ in low- and middle-income countries demonstrated low levels of income and lack of financial resources as major factors affecting enrolment [23]. Household income directly contributes to the affordability and is positively correlated with willingness to pay the premium as found by different studies [23-26, 29, 34, 37]. This finding is akin to the finding in the evaluation of Ethiopia's $\mathrm{CBHI}$ which documented that 39 percent households mentioned registration fees and premium are not affordable [19]. Other studies conducted in Ghana, Nigeria, Mali, and Senegal also reported that flat-rate premium restricted enrolment decision of the poor [23, 31, 35-36]. This is the very reason why there is a targeted subsidy for the poor in Ethiopia's CBHI design (an estimated 10\% in each district) [33] although there is always a huge challenge in identifying who the poor is or the indigent population expected to benefit from the subsidy [40].

On the contrary, a previous study in Ethiopia reported that household's socioeconomic status does not inhibit uptake of $\mathrm{CBHI}$ and found that most food-insecure households were substantially more likely to enroll [32]. This was done in a setting where poor households were participating in a productive safety net program which targets chronically food insecure households. Another study reported that participation of households in both social protection programs i.e. community based health Insurance and productive safety net program were associated with a 5 percent increase in livestock and a 27 percent decline in debt which in turn affords greater protection to vulnerable households against multiple risks [21].

The findings in the study depended on the feedback provided by the respondents which may be subject to some form of respondent bias. The strength of this study is the use of combined quantitative and qualitative approach which helped in triangulating the information provided by the respondents and gave better clarity and understanding of the quantitative information. In addition, this is the first study done in this region of Ethiopia on this topic to our knowledge.

\section{Conclusions}

The enrollment for community-based insurance was determined by being well informed about CBHI, Household income, and being a member of solidarity groups at community level. Given the early stage of implementation, enhancing sensitization of the community about the scheme using various community platforms, promotion of the existing community based solidarity groups/associations, diligent targeting 
the poor households and whilst ensuring linkage with any existing social protection program would help to increase enrolment for the scheme.

\section{Abbreviations}

CBHI-Community Based Health Insurance

SHI-Social Health Insurance

LMIC-Lower Middle-Income Countries

FGD-Focus Group Discussion

KII-Key Informant Interview

AOR-Adjusted Odds Ratio

COR-Crude Odds Ratio

\section{Declarations}

\section{Ethical approval and consent to participate}

Ethical clearance was granted by Ethics Review Committee of Somali Regional Health bureau, Ethiopia. Support letter was given by Bureau addressed to study districts and verbal consent was taken from study participants after being given adequate information about the study. More-over, anonymity and confidentiality were kept by omitting personal identifiers.

\section{Consent for publication}

N/A

\section{Availability of data and material}

All data generated or analyzed during this study are included [and its supplementary information files].

\section{Competing Interests}

The authors declare that they have no competing interests.

\section{Funding}


The authors received no funding from any source.

\section{Authors' contributions}

- Conceptualization: AEF, ATA, OO

- Data curation: AEF, ATA

- Formal analysis: AEF, ATA.

- Methodology: AEF, ATA, OO

- Supervision: AEF, ATA.

- Writing \pm original draft: AEF, ATA, OO

- Writing \pm review \& editing: AEF, ATA, AR

\section{Acknowledgement}

We would like to extend our deepest gratitude to the Somali Regional Health Bureau for facilitating and giving support letter for this study. Our appreciation goes to the data collectors and study participants for consenting to participate the data collection process.

\section{References}

1. World Health Organization. Universal Health Coverage.https://www.who.int/health-topics/universalhealth-coverage(accessed 15 June 2021).

2. Carrin G, Mathauer I, Xu K, Evans D. Universal coverage of health services: tailoring its implementation. Bull World Health Organ 2008; 86: 857-63.

3. Garrett L, Chowdhury M, Pablos Mendez A. All for universal health coverage. Lancet 2009; 374 : 1294-99.

4. O'Donnell O, van Doorslaer E, Rannan-Eliya RP, et al. Who pays for health care in Asia? J Health Econ 2008; 27: 460-75.

5. Aman A, Gashumba D, Magaziner I, Nordström A. Ethiopia Federal Ministry of Health, Addis Ababa, Ethiopia (AA); Rwanda Ministry of Health, Kigali, Rwanda (DG); Clinton Health Access Initiative, Boston, MA, USA (IM); and Ministry for Foreign Affairs, Government of Sweden, S-103 33 Stockholm, Sweden (AN).

6. Xu K, Evans D, Kawabata K, Zeramdini R, Klavus J, Murray CJL. Household catastrophic health expenditure: a multicounty analysis. Lancet 2003; 362: 111-17.

7. Spaan E, Mathijssen J, Tromp N, McBain F, Have At, Baltussena R. The impact of health insurance in Africa and Asia: a systematic review. Bull World Health Organ 2012; 90:685-692A 
8. Xu K, Evans D, Carrin G, Aguilar A, Musgrove P, Evans T. Protecting households from catastrophic health spending. Health Affairs 2007; 26: 972-83

9. Van Hees et al. Leaving no one behind? Social inclusion of health insurance in low- and middleincome countries: a systematic review. International Journal for Equity in Health (2019) 18:134.

10. Federal Ministry of Health 1998. Ethiopia Health Care Financing Strategy. Addis Ababa, Ethiopia.

11. Federal Ministry of Health. Health Care Financing Strategy 2017-2021. Addis Ababa, Ethiopia.

12. Ethiopia's Seventh National Health Accounts, 2016/2017. Addis Ababa, Ethiopia.

13. Ethiopia Health Insurance Agency. CBHI Members' Registration and Contribution 2011-2020GC. CBHI Trend Bulletin. Sept 2020.

14. World Bank Group. Poverty data. Ethiopia. www.worldbank.org/poverty

15. Somali Region Health Bureau. Community Based Health Insurance (CBHI) implementation status brief 2020.

16. CDC. (2019) Epi Info ${ }^{\text {TM }}$, Division of Health Informatics \& Surveillance (DHIS), Center for Surveillance, Epidemiology \& Laboratory Services (CSELS. https://www.cdc.gov/epiinfo/userguide/statcalc/unmatchedcasecontrol.html

17. Nageso D, Tefera K, Gutema K (2020). Enrollment in community-based health insurance program and the associated factors among households in Boricha district, Sidama Zone, Southern Ethiopia; across-sectional study. PLoSONE 15(6): e0234028. https://doi.org/10.1371/journal.pone.0234028

18. Mirach TH, Demissie GD, Biks GA. Determinants of community-based health insurance implementation in west Gojjam zone, Northwest Ethiopia: a community based cross sectional study design. BMC Health Services Research (2019) 19:544.

19. Christiana O, Olayinka I. Community based health insurance scheme: preferences of rural dwellers in Federal capital territory Abuja, Nigeria. Journal of public health in Africa. 2018; 9(540):57.

20. Ethiopian Health Insurance Agency. Evaluation of Community based health insurance pilot schemes in Ethiopia. May 2015.

21. Donfouet and Mahieu: Community-based health insurance and social capital: a review. Health Economics Review 2012 2:5.

22. Shigute, Zemzem; Strupat, Christoph; Burchi, Francesco; Alemu, Getnet; Bedi, Arjun S. (2017): The Joint Effects of a Health Insurance and a Public Works Scheme in Rural Ethiopia, IZA Discussion Papers, No. 10939, Institute of Labor Economics (IZA), Bonn

23. Basaza R, Criel B, Van der stuyft P. Low enrolment in Ugandan Community Health Insurance Schemes: underlying causes and policy implications. BMC Health Services Research 2007, 7:105 doi:10.1186/1472-6963-7-105.

24. Adebayo EF, Uthman OA, Wiysonge CS, Stern EA, Lamont KT, Ataguba JE. A systematic review of factors that affect uptake of community-based health insurance in low-income and middle-income countries. BMC Health ServRes. 2015;15(1). 
25. Kebede A, Gebreslassie M, Yitayal M. Willingness to pay for community-based health insurance among households in the rural community of Fogera District, North West Ethiopia. International Journal of Economics, Finance and Management Sciences 2014; 2(4): 263-269

26. Demissie GD, Atnafu A. Barriers and Facilitators of Community-Based Health Insurance Membership in Rural Amhara Region, Northwest Ethiopia: A Qualitative Study. ClinicoEconomics and Outcomes Research 2021:13 343-348

27. Nosratnejad S, Rashidian A, Mehrara M, Sari AA, Mahdavi G, \& Moeini M. Willingness to Pay for Social Health Insurance in Iran. Global Journal of Health Science; Vol. 6, No. 5; 2014

28. Noubiap JJ, \&, Joko WYA, Obama JMN, Bigna1 JJR. Community-based health insurance knowledge, concern, preferences, and financial planning for health care among informal sector workers in a health district of Douala, Cameroon. Pan African Medical Journal. 2013; 16:17. doi:10.11604/pamj.2013.16.17.2279

29. Jacobs B, Bigdeli M, Van Pelt M, Ir P, Salze C, Criel B. Bridging community-based health insurance and social protection for health care - a step in the direction of universal coverage? Tropical Medicine and International Health doi:10.1111/j.1365-3156.2007. 01983.x volume 13 no 2 pp 140143 February 2008

30. Djahini-Afawoubo DM, Atake E. Extension of mandatory health insurance to informal sector workers in Togo. Health Economics Review (2018) 8:22 https://doi.org/10.1186/s13561-018-0208-4.

31. Tesfaye Y, Ayenew Z. Determinants of Participation in Community Based Health Insurance: A Study among High School and Preparatory School Teachers in Adama town, Oromia Region, Ethiopia. Horn of Africa Journal of Business and Economics (HAJBE), 2019, 2(1), PP: 12- 22.

32. Odeyemi: Community-based health insurance programmes and the national health insurance scheme of Nigeria: challenges to uptake and integration. International Journal for Equity in Health 2014 13:20.

33. Derseh A, Sparrow R, Yilma Z, Alemu G, Arjun S. Bedi AS. Enrolment in Ethiopia's Community Based Health Insurance Scheme. Institute of Social Studies.www.iss.nl.

34. Abt Associates Inc. Ethiopia's Community-based Health Insurance: A Step on the Road to Universal Health Coverage. www.hfgproject.org.

35. Minyihun A, Gebregziabher MG, Gelaw YA. Willingness to pay for community-based health insurance and associated factors among rural households of Bugna District, Northeast Ethiopia. BMC Res Notes (2019) 12:55 https://doi.org/10.1186/s13104-019-4091-9.

36. Kusi A, Enemark U, Hansen KS, Asante FA. Refusal to enroll in Ghana's National Health Insurance Scheme: is affordability the problem? Int J Equity Health. 2015;14(1):2.

37. Jahangir AM. Khan and Sayem Ahmed. Impact of educational intervention on willingness-to-pay for health insurance: A study of informal sector workers in urban Bangladesh Health Econ Rev. 2013; 3:12. https://doi.org/10.1186/2191-1991-3-12.

38. Akwaowo CD, Umoh I, Motilewa O, Akpan B, Umoh E, Frank E, Nna E, Okeke U and Onwujekwe OE (2021) Willingness to Pay for a Contributory Social Health Insurance Scheme: A Survey of Rural 
Residents in Akwa Ibom State, Nigeria. Front. Public Health 9:654362. doi:

10.3389/fpubh.2021.654362.

39. Ashagrie B, Biks GA, Belew AK. Community-Based Health Insurance Membership Dropout Rate and Associated Factors in Dera District, Northwest Ethiopia. Dove Press journal: Risk Management and Healthcare Policy 2020:13 2835-2844.

40. Alhassan RK, Nketiah-Amponsah E, Arhinful DK (2016) A Review of the National Health Insurance Scheme in Ghana: What Are the Sustainability Threats and Prospects? PLoS ONE 11(11): e0165151. doi:10.1371/journal. pone.0165151.

41. Fenny AP, Kusi A, Arhinful DK and Felix Asante FA. Factors contributing to low uptake and renewal of health insurance: a qualitative study in Ghana. Global Health Research and Policy (2016) 1:18 DOI 10.1186/s41256-016-0018-3.

42. Fadlallah R, El-Jardali F, Hemadi N, Morsi RZ, Samra CA, Ahmad A, Arif K, Hishi L, Gladys HoneinAbouHaidar G, AkI EA. Barriers and facilitators to implementation, uptake and sustainability of community-based health insurance schemes in low and middle-income countries: a systematic review. International Journal for Equity in Health (2018) 17:13 DOI 10.1186/s12939-018-0721-4.

43. Nshakira-Rukundo E, Mussa EC, Nshakira N, Gerber N, von Braun J. Determinants of enrolment and renewing of community-based health insurance in households with under- 5 children in rural southwestern Uganda. Int J Health Policy Manag. 2019;8(10):593-606. doi:10.15171/ijhpm.2019.49.

\section{Figures}




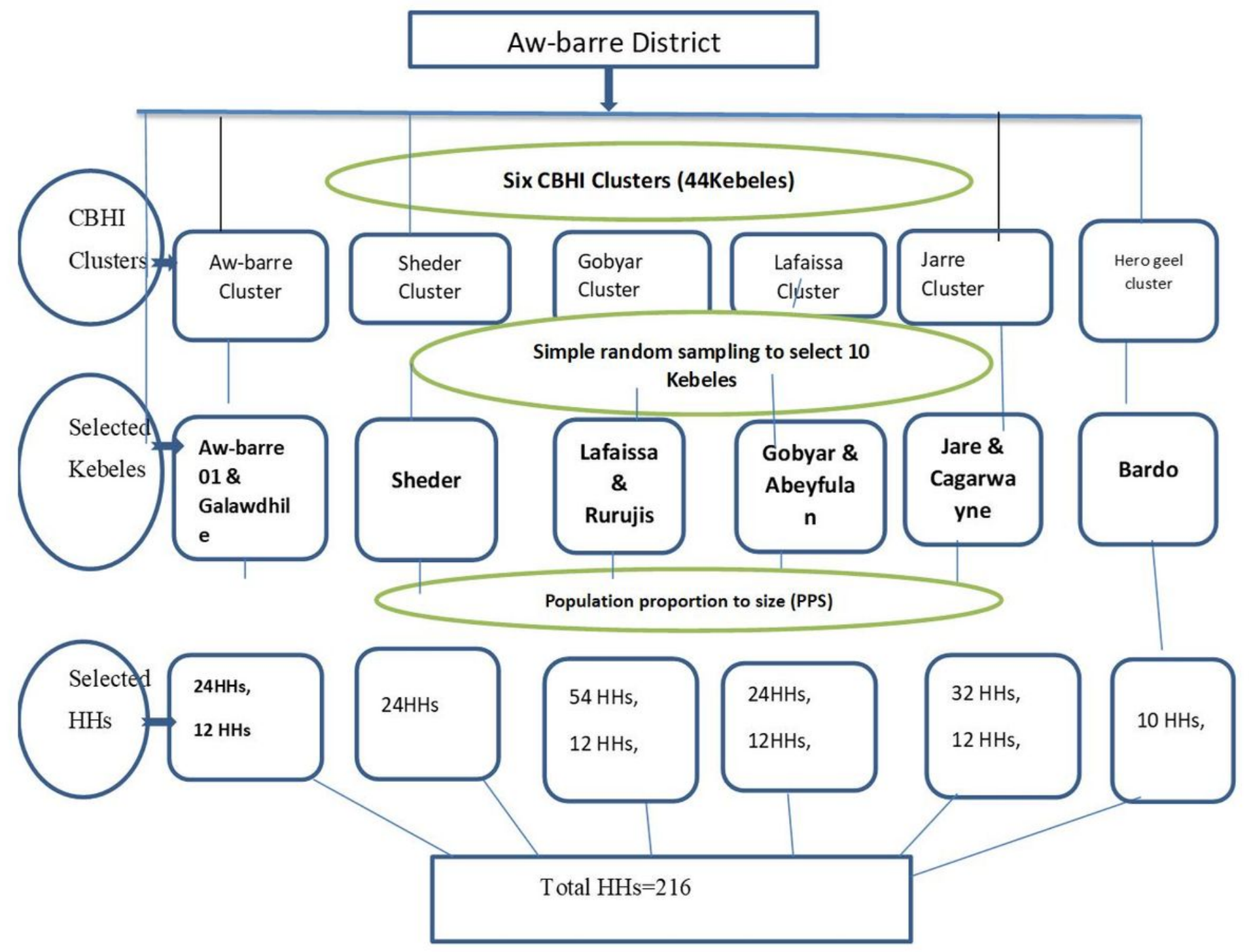

Figure 1

Schematic presentation of the sampling procedure.

\section{Supplementary Files}

This is a list of supplementary files associated with this preprint. Click to download.

- CBHIDATA.xlsx 